\title{
UNDERSTANDING THE ROLES OF RHETORICAL DEVICES AND INTERTEXTUALITY IN PROMOTIONAL DISCOURSE
}

\author{
Muhammad Fakhrullah Zulkipli ${ }^{1}$ \\ Department of English Language and Literature \\ International Islamic University Malaysia \\ (Email: iium.fakhrullah.zul@gmail.com) \\ Adlina Ariffin ${ }^{2}$ \\ Corresponding author \\ Department of English Language and Literature \\ International Islamic University Malaysia \\ (Email: adlina@iium.edu.my)
}

Accepted date: $25-06-2019$

Published date: 11-07-2019

To cite this document: Zulkipli, M. F., \& Ariffin, A. (2019). Understanding the Roles of Rhetorical Devices and Intertextuality in Promotional Discourse. International Journal of Heritage, Art and Multimedia, 2(5), 90-107.

DOI: $10.35631 /$ ijham. 25008

\begin{abstract}
This paper examines the interplay of rhetorical devices and intertextuality in projecting the branding image of promotional discourse i.e. online advertisements of three common fast food chains in Malaysia. This study, which adapted the framework of rhetorical devices developed by Michalik and Michalska-Suchanek (2016), investigated the utilisation of rhetorical devices and intertextual elements in the advertisements by McDonald's, Kentucky Fried Chicken (KFC) and Texas Chicken. The findings from the study show that there is a great difference in the use of the rhetorical devices by the three fast food chains where Texas Chicken employed the highest number in the types of devices (9 out of 14 types) and KFC utilized the least elements (4 out of 14 types). Halal logo is also used as a common rhetorical device in the advertisements to exert the permissibility/halalness of the food. An examination on the intertextuality of the advertisements brings to light the crucial use of pop culture and local socio-cultural elements in promotional discourse. It could be deduced from the study that among the factors that shape the advertisements are product reputation, modern popular culture, consumers' beliefs and cultural norms.
\end{abstract}

Keywords: Rhetorical Devices; Intertextuality; Promotional Discourse; Advertisements

\section{Introduction}

The effectiveness of any advertisements lies in its power of persuasion. Tom and Eves (1999) highlight that advertisements are usually crafted in a persuasive tone for they are not merely meant to inform customers but also to persuade them to purchase products or services. For such purpose, the use of rhetorical devices in advertisements is crucial to attract potential customers. 
In this era where business competition is most stiff, companies are allocating a huge amount of their budget on advertising. The competition is further exacerbated with the use of social media and internet as important promotional engines. Kim and Ko (2012), who studied the effect of social media marketing (SSM) on customers' purchase intention, found a strong positive relationship between both variables in the sales of luxury brands. This indicates the significant influence of the internet in increasing product sales. Furthermore, a study conducted by Hartnett, Kennedy, Sharp, and Greenacre (2016) shows that there is a significant relationship between creative devices and sales effectiveness of online products. They highlighted that devices such as jokes and music could affect consumers' behaviour towards the products.

However, Wolk (2018) highlights that the advertising industry really needs to be more innovative and artistic in order to compete in the digital marketing. He emphasizes the fact that contemporary young writers lack creativity in designing advertisements when companies are trying to lure customers through gaining their interest and trust in the products instead of merely enjoying the 'content' of the advertisements. He claims that companies are too afraid to go for creative designs and slogans and hence, risk the advertisements not being remembered by the audience.

While many studies have investigated aspects of this promotional genre (Al-Siyami, 2013; Burgersa, Konijn, Steen, and Iepsma, 2015; Fredericks John, 2015; Hamisah, Ezhar, Jusang, Mohd Nizal and Azhani, 2016; Mazzali-Lurati and Pollaroli, 2016; McQuarrie and Mick, 2009; Michalik and Michalska-Suchanek, 2016; Miller and Toman, 2014; Shaizatulaqma, Khairul Anwar and Ishak, 2016; Tom and Eves, 1999; Skorupa and Duboviciene, 2015), there is a dearth of studies looking into how rhetorical devices and intertextuality of online advertisements play a role in projecting the image of fast food products and persuading consumers to purchase them.

Hence, the present study is conducted to investigate the validity of Wolk's (2018) claim in relation to the Malaysian fast food industry. Simultaneously, it hopes to enrich studies on promotional discourse in this particular area. This industry, with a global revenue of $\$ 570$ billion, makes up more than 50\% of the total restaurant sector (Fast Food Industry Analysis, 2018). In Malaysia, it is one of the fastest booming industries due to the increasing tendency of Malaysians to adopt Western style of food consumption (Pangali, 2006 in Ryan, Ghazali, Mohsin, 2011). Hence, the objectives of the study are to 1) identify the societal influence in the shaping of the language of advertisements or the promotional discourse by analyzing the rhetorical devices and elements of intertextuality and 2) analyse aspects of creativity and crosscultural variations represented in the promotional discourse. These objectives shall be achieved by investigating how rhetorical devices and intertextuality are utilised in the online promotion of three most common fast food chains in Malaysia - McDonald's, Kentucky Fried Chicken (KFC) and Texas Chicken.

\section{Literature Review}

\section{Interdiscursivity and Intertextuality}

Interdiscursivity and intertextuality are the two main theoretical concepts underpinning this study. Interdiscursivity is very much entrenched in advertisements. It refers to "the mixing of diverse genres, discourses or styles associated with institutional and social meanings in a single text" (Wu, 2011, p.96). This concept is closely related to the model of intertextuality because 
"transformations between genres are examples of an intertextual relation" (Rahm, 2006, p.197). According to Fairclough (1993), language use is "always simultaneously constitutive of social identities, social relations, and system of knowledge and belief" (p. 134). The language use has always been shaped by how the society works or behaves. Language use can be socially shaping or socially constitutive. He also highlights that each discursive event has three points of view that must be critically analysed. First, the discourse could be a text that has been written or spoken. Second, the discourse practice involves the production and interpretation of the text. Lastly, the discourse must be treated as a part of social practice. Within these perspectives, a discourse must be analysed critically to draw the connection between discourse and society.

An equally important element in advertisements is intertextuality. The term was officially introduced by Julia Kristeva in 1966 (Prentice and Barker, 2017). Kristeva opined that a text is not an isolated piece of work but rather it is conceptualised based on various referents such as discourse, texts and genres (Elmo Raj, 2015). Thus, readers of a newly produced text are able to make references to the "internal constituents of the text and a history of knowledge, conventions and experiences relevent to the discourse that are encountered" (Al-Syima, 2013, p.42).

Intertextuality in advertisements could give a big impact to the audience as it could trigger users's attention and memory to their previous experiences and original sources of the text that are parallel in content and form (Al-Syima, 2013; Chandler, 1997; Cook, 2001; Tanaka, 1994; Xin, 2000,). According to Ali \& Aslam (2016), "Discourse should not be considered in isolation; rather, discourses act upon and influence one another in an act of intertextuality" (p.26). In short, intertextuality means a combination of previous texts into a new text whereby the previous discourses are possibly influencing, somehow and somewhere, along a new designed discourse.

The dependency and link between both texts give rise to the possibility for similar elements or genres to be attached to the new text. Indirectly, intertextuality presents a sense of familiarity and deeper understanding among the target readers when they come across the similar elements in the text that they are reading.

Meanwhile, Al-Siyami (2013) believes that intertextuality is a weapon for writers who wish to manipulate the readers. New texts will be injected with the elements from prior texts and the new texts will get involved in the process of restructuring on the way that it should be done prior to the production of the text. Al-Siyami (2013) also indicates that intertextuality is a process of putting a reference inside the text which will "play around" with the readers' memory to the original source of the elements. Thus, intertextuality will help the writer to produce a text that is absolutely new but with the twist of restructuring and remixing which will help the text to be more relatable and memorable to the readers.

Nemcokova (2014) highlights that the process of delivering advertisements using register and text-form which seem familiar to the readers is a very common practice among advertising team. The sense of familiarity will create "self-conciousness" among the audience of the advertisements which will enable them to make sense of previous experiences or memories that they have through the narration of the advertorials.

Based on this fundamental understanding, the present study aimed to identify the societal influence in the shaping of the language of advertisements or the promotional discourse by analyzing the rhetorical devices and elements of intertextuality. 


\section{Promotional Discourse}

Due to modernity, the discourse throughout the world has injected some elements of capitalism which brings us to the promotional culture or consumer culture. This contemporary discursive practice has three influences which are -1) post-traditional, 2) reflexivity, and 3) promotional or consumer culture. These occurrences and factors affecting the discourse practice in the contemporary society has resulted in the marketization of the public discourse (Fairclough, 1993).

Realizing the transformation from traditional discourse practice towards the contemporary discursive event, Bhatia (2005) has put forth promotional discourse as a means to engage the discourse with the societal expectations and needs. He stresses that promotional discourse has changed the process of writing into a form of art as a means for survival and cross-cultural variations. Writers are frequently struggling to enhance the creativity and the language used so that writing would appeal to the targeted readers. He concludes that these rhetorical and lexicogrammatical resources have helped the public discourse to be more creative and innovative. Due to this fact, this study aspires to investigate aspects of creativity and cross-cultural variations represented in the promotional discourse of three fast food chains in Malaysia. As a multicultural and multi-religious society, it is expected that the findings will be a vibrant representation of Malaysian colourful populace.

\section{Rhetorical Devices}

Rhetorical devices, being the main focus of analysis in the study, refer to artful mechanisms which are commonly used in advertisements with the intention to persuade the target audience (Harris, 2016; Michalik and Michalska-Suchanek, 2016; Miller and Toman, 2015; Tom and Eves, 1999). These devices are commonly found in advertising media such as slogans, images, logos, etc. Michalik and Michalska-Suchanek (2016) state that by using rhetorical tones with appropriate channel and method, the speaker or informer can directly gain the trust of his/her audience to agree with their points and arguments which will affect their decision-making. They emphasise that advertising is not only about designing a good case for the target audience but also conveying information in a way that conforms to the emotions of every human being. Moreover, Tom and Eves (2014) explain that rhetorical devices are linguistic features that can be used to create slogans or advertising copy. Besides that, Skorupa and Duboviciene (2015) emphasize the importance for advertorials to possess emotional appeal which would touch the audience's emotion, regardless negative or positive emotions. Rhetorical devices could also be working devices to add special effects on the advertisements which will appeal to the potential audience.

\section{Methodology}

A corpus of 24 online advertisements from Kentucky Fried Chicken, McDonald's and Texas Chicken (8 from each company) were used as the sample in this study (Please refer to Appendices I to VI for a few of the advertisements). These fast food chains were selected based on their popularity as major companies serving fast food in Malaysia. The choice of the online advertisements was made based on random sampling of the texts available on the internet from January 2017 to January 2018.

This study employed the framework of rhetorical devices developed by Michalik and Michalska-Suchanek (2016) in analysing the rhetorical devices in the corpus of online advertisements. The elements of the framework are described as follows: - 


\begin{tabular}{|c|c|}
\hline & Elements and definitions \\
\hline 1) & $\begin{array}{l}\text { Alliteration - an occurrence of the same letter or same sound at the beginning of a } \\
\text { word or a phrase; first same consonant sound and occurs in a series. } \\
\text { e.g. Today, Tomorrow, Toyota (Toyota) }\end{array}$ \\
\hline 2) & $\begin{array}{l}\text { Hyperbole - an exaggeration of a claim made by particular authors to make sure } \\
\text { that the products will look bombastic and extravagant from what they really are } \\
\text { e.g. Chevrolet. An American revolution (Chevrolet) }\end{array}$ \\
\hline 3) & $\begin{array}{l}\text { Rhymes - the same sound is repeated several times for an artful effect. } \\
\text { e.g. Grace...space...pace (Jaguar) }\end{array}$ \\
\hline 4) & $\begin{array}{l}\text { Repetition - repetition of certain words in a phrase or in a sentence to emphasize } \\
\text { the message. } \\
\text { e.g. New thinking. New possibilities (Hyundai) }\end{array}$ \\
\hline 5) & $\begin{array}{l}\text { Personification - an idea, an animal or a thing, given the human attributes. } \\
\text { e.g. The car that cares (KIA) }\end{array}$ \\
\hline 6) & $\begin{array}{l}\text { Idiom - intended to make the phrases attractive without pointing out the literal } \\
\text { meaning. } \\
\text { e.g. Love at first flight (Virgin America) }\end{array}$ \\
\hline 7) & $\begin{array}{l}\text { Oxymoron - Words that have opposite meanings. } \\
\text { e.g. The little big car (Renault) }\end{array}$ \\
\hline 8) & $\begin{array}{l}\text { Imperative mood - manipulated to be a trigger to the audience so that they will be } \\
\text { persuaded to buy the products and to instill the idea of buying the products into their } \\
\text { mind; used to suggest or propose something in most natural way. } \\
\text { e.g. Do something memorable (Toyota Aygo) }\end{array}$ \\
\hline 9) & $\begin{array}{l}\text { Pronouns - the usage of pronouns that will make reader feels relatable; } \\
\text { - the use of pronouns, especially the second person singular or plural pronoun } \\
\text { "you", or its possessive form "your", as well as the first person plural pronoun } \\
\text { "we" or its possessive form "our" are used by copywriters to emphasize that the } \\
\text { message is addressed to the reader (you) (Michalik \& Michalska-Suchanek, 2016, } \\
\text { p.52). } \\
\text { e.g. With your miles you can now fly further (Qatar Airways) }\end{array}$ \\
\hline 10) & $\begin{array}{l}\text { Verbs - zooming in the focus of the message to the readers. } \\
\text { e.g. Just imagine what Citroen can do for you (Citroen) }\end{array}$ \\
\hline 11) & $\begin{array}{l}\text { Nouns - emphasizing the values and characteristics. } \\
\text { e.g. Design. Innovation. Performance (Jaguar XF) }\end{array}$ \\
\hline 12) & $\begin{array}{l}\text { Adjectives - used to tell the audience the taste, the look, the feel, and everything } \\
\text { related to the properties of the products; giving the power of persuasion through the } \\
\text { degree of the items. } \\
\text { e.g. More economical. Less pollutant (Peugeot) }\end{array}$ \\
\hline
\end{tabular}

Burgersa, Konijn, Steen, and Iepsma (2015) have included irony and metaphor as elements in their study on rhetorical devices in slogans and advertising. Irony, according to Burgersa et.al (2015) is an evaluation which could be contradicting to the intended one, while metaphor is introduced as a comparison made from the original source to the target domain. These two items are powerful in initiating creative thought among the readers/audience due to their complexity and the way they act as a "puzzle" which help the advertisements to be more memorable and 
interesting. Due to their importance, these two items were included in the analytical framework of the rhetorical devices making the total items fourteen.

\section{Results and Discussion}

A summary of the rhetorical devices used by the three fast food chains is presented below.

Table 1: Frequency of Rhetorical Devices Used by The Three Fast Food Chains

\begin{tabular}{|c|c|c|c|}
\hline $\begin{array}{l}\text { Rhetorical } \\
\text { Devices }\end{array}$ & $\begin{array}{l}\text { Texas } \\
\text { Chicken }\end{array}$ & McDonald's & KFC \\
\hline Alliteration & 3 & 2 & \\
\hline Hyperbole & 8 & & 1 \\
\hline \multicolumn{4}{|l|}{ Rhymes } \\
\hline Repetition & 7 & 1 & \\
\hline Personification & & 5 & \\
\hline \multicolumn{4}{|l|}{ Idiom } \\
\hline \multicolumn{4}{|l|}{ Oxymoron } \\
\hline $\begin{array}{l}\text { Imperative } \\
\text { mood }\end{array}$ & 21 & 9 & 22 \\
\hline Pronouns & & 3 & \\
\hline Verbs & 2 & 5 & \\
\hline Nouns & 1 & 2 & 1 \\
\hline Adjectives & 22 & 4 & 4 \\
\hline Metaphor & 1 & & \\
\hline Irony & 1 & 2 & \\
\hline Total & 66 & 28 & 28 \\
\hline
\end{tabular}

Table 1 shows the frequency of each rhetorical device found in the advertisements for Texas Chicken, McDonald's, and KFC. A total of 9 items of rhetorical devices were identifed in the advertisements of Texas Chicken, 9 items in McDonald's and 4 items in KFC. It is also obvious from the data above that Texas Chicken showed the highest frequency in the use of the 9 rhetorical devices with 66 occurrences while McDonald's and KFC both showed similar number of occurrences of 28 .

\section{Texas Chicken}

The analysis indicated that advertisements of Texas Chicken contained 9 items of the rhetorical devices which are as follows: - 
1) Alliteration: In this case, Texas Chicken used several connotations of alliteration in their advertisements i.e. "Merry Meals", "More Spice. More Crunch. More Value", and "Mega Meals" where the focus is on the use of the $/ \mathrm{m} /$ sound at the beginning of every word and every phrase.

2) Hyperbole: The hyperbole used in Texas Chicken advertisements are "Mega Meals" and " $100 \%$ Fresh Chicken". Although the latter would be arguable to say that it is not an exaggeration, it would be inappropriate to claim that a meal would be $100 \%$ fresh if we are talking about food from a fast food chain. Hence, with such claim, the company has over-promoted the chicken as fresh as they can guarantee that it is $100 \%$ fresh while it is quite impossible to do so when they are served to the customers.

3) Repetition: For the advertisements promoted by Texas Chicken, they utilised the slogan " $100 \%$ fresh chicken. Fresh from the farm" almost in all of their advertisements. The word "fresh" is being repeated twice in that slogan probably because they want to place an emphasis on the freshness of their fried chicken product.

4) Imperative mood: Texas Chicken used this device to persuade their customers to try their products i.e. "RM 5.90 for limited time only", "From only RM 10.90", "RM 9.90 each with any purchase". From the examples given, a pattern can be identified where the company tries to convince customers to act quickly to purchase their products because the prices offered are within a limited time.

5) Verbs: Texas Chicken also used verbs in their advertisements, albeit the number is only 2 occurrences. Among the advertisements analysed in this study, it was found that there was an advertisement which used the verbs "Fry" and "Dip". The use of the verbs suggest to the audience that the product has gone through the process of frying and dipping into the sauce. Moreover, it is also part of the marketing technique to tap into the senses of the buyers.

6) Nouns: An advertisement in the corpus uses a noun in a slogan to promote a burger produced by Texas Chicken which reads 'Fiery 'crunch' burger". Crunch relates to the sound made by someone when he/she bites something that is crunchy. The word conjures the idea that the "crunch" sound will be heard when customers try the burger. It also gives the idea of the enjoyment and satisfaction when they take their bite into the burger.

7) Adjectives: This item has the highest occurrence in the advertisements analysed in this study. In the products advertised by Texas Chicken, there were several adjectives used and attached to the slogans or appear independently. The common adjectives used in the advertisements are "new", "limited", "free", "fresh". The adjectives are used to promote the items especially the new products introduced by the company. The adjectives mentioned serve the purpose of notifying customers on the availability of the products and the properties of the products, other than trying to sell the products along with a few "free" items.

8) Metaphor: Fry ' $N$ ' Dip: with Nacho cheese is a slogan found in one of the advertisements. The replacement of the word "and" with the letter " $\mathrm{N}$ " aims to symbolize the Nacho cheese that the company is promoting to the audience. Furthermore, the replacement of "and" to "N" gives the slogan a catchy effect.

9) Irony: In one of the advertisements, the researcher found that a word "cooler" was used to indicate both noun and adjective for the tote bag promoted along the Texas Chicken products. The slogan reads "Cooler tote bag" which probably aims to give a literal connotation as a bag for the customers to keep their coolers. However, "cooler" could also mean something which is 'cool' which indicates something that will never go out of style and gives an adjective connotation to the tote bag. 


\section{McDonald's}

This study also analysed 30 occurrences of rhetorical devices from 8 advertisements by McDonald's. The use of rhetorical devices in the advertisements can be seen as follows: -

1) Alliteration: The use of alliteration can be seen in the McDonald's slogan "Mix \& Match". Both words "mix" and "match" start with the sound $/ \mathrm{m} /$. Thus, the condition satisfies the occurrence of alliteration in the advertisements.

2) Repetition: In the McDonald's advertisements, there is a repetition which is included in one of the advertisements. The slogan - "Spice, Spice Baby" - has the word "spice" that is repeated twice. The repetition of the word "spice" is made to give the emphasis on the amount of spice that they include in their advertised products.

3) Personification: In the case of McDonald's advertisements, there are 5 occurrences of personification. "Spice, Spice Baby" is one of the examples from the advertisements which shows that the food product is referred to using a term of endearment "Baby". Besides that, there is another advertisement that illustrates the conversation between the food products and the audience. The dialogues are - "We look good together", "You're right for me", and "Chillin' with my sweetie". Apart from that, there are several humane remarks which are also included in the advertisements such as "My love from the grill" which refers to the burger as a lover.

4) Imperative mood: In the advertisements by McDonald's, there are several slogans that utilise imperative mood. "Mix \& Match" and " $1+1=$ RM 5.99" tell the audience that they can mix and then match the food products promoted in the advertisements. The latter indicates that if customers buy two items in the advertisements, they will only need to pay RM 5.99.

5) Pronouns: In the McDonald's advertisements, three pronouns are found which are "you", "we" and "me". It can be understood that the pronouns are meant to make the advertisements closer to the potential consumers and when they see the advertisements, they will directly feel the connection.

6) Verbs: In the advertisements by McDonald's, several verbs are identified such as "mix", "match", "look", "chilling". These monosyllabic verbs were used to encourage customers to take actions immediately.

7) Nouns: In the Prosperity Burger advertisement, it uses nouns such as "beef" and "chicken" to indicate the types of burgers they produce. In this context, the advertiser is trying to attract two groups of customers - 1) those who favour chicken meat and 2) those who would go for beef instead. By emphasizing the two words, readers would be notified that Prosperity Burger comes in both chicken and beef.

8) Adjectives: Adjectives that can be found in McDonald's are - "spicy", "new", "golden". These adjectives are used to give the identity to the products and to define how it looks like or how it tastes like. The adjective "new" is a very common adjective that can be seen in every advertisement when companies are trying to promote their new products.

9) Irony: An element of irony can be seen in the advertisement particularly in the projection of " $1+1=\mathrm{RM}$ 5.99". A normal calculation would show that $1+1=2$, however such calculation has been creatively twisted to convey to customers that if they buy one item from the menu and buy another one from another menu, they will get RM 5.99 as a total price for both items. In this case, irony helps the advertisements look mindblowing and humorous which could help the advertisements to be memorable to the readers. 


\section{Kentucky Fried Chicken}

The usage of rhetorical devices in KFC advertisements can be analysed as follows: -

1) Hyperbole: In the advertisements by KFC, there is an occurrence of hyperbole which is exaggerating the fact that the Thai sauce is so authentic even the Thais want to have it. Although it is never guaranteed how authentic the sauce is, putting such remark is seen as an initiative of KFC Malaysia to over-sell their product so that the potential customers would come to the outlet and have a taste of it because of the exaggeration made by the claim.

2) Imperative mood: "It's better to share" is one of the examples of imperative mood used by KFC. Imperative mood has the highest occurrence compared to the other 3 items (Refer to Table 1). Apart from that, KFC seems to favour putting the product price in the advertisements. This is probably to inform customers that they provide affordable price compared to other fast food chains which somehow could persuade the readers to choose their products instead, as a choice for fast food restaurant.

3) Nouns: In one advertisement, the noun "bargain" is used to promote the bucket meal by KFC. The noun "bargain" is used to indicate to customers that purchasing the bucket meal will be a great option for them to buy a large quantity of the product at a cheaper price.

4) Adjectives: "So authentic" and "So good" are two phrases which indicate the authenticity and the goodness of the KFC products. The adjectives "authentic" and "good" define the products sold and they emphasize the good quality that the products possess. In doing so, it can help to build trust in the readers where it will affect their decision to buy and try the products.

The findings above clearly indicate that all three fast food companies do utilize majority of the rhetorical devices in their advertisements albeit at different frequency. Indirectly, this shows that the advertisers do make attempts to instill creativity in their manipulation of the devices in order to capture the attention of the customers and gain their interest in purchasing the products. This result negates the idea mentioned by Wolk (2018) that companies are apprehensive to produce innovative slogans and designs. One clear justification can be seen in the Personification of the products which is indeed a very fascinating way in representing the food. For instance, the phrase "My love from the grill" in the McDonald's advertisement indicates that the burger is perceived as a lover rather than mere food.

Moreover, the utilization of Verbs in the advertisements using monosyllabic action words such as 'Fry', 'Dip', 'mix', 'match' is an appealing technique to subtly persuade customers to take immediate actions (Refer to Appendix VI). On this, Zhang, Lorache, and Richard (2017) state that verbs are found to be more noticeable to the readers compared to pronouns and adjectives. Their study indicate that Chinese people tend to favour verbs as a tool to persuade them to buy something. However, in this study, Adjectives is a common device found in the advertisements of all three fast food chains with a total of 30 occurrences. Adjective words such as 'fresh', 'spicy', 'new', 'authentic' and 'fiery' (Refer to Appendix V) are able to stimulate the readers' senses and prompt them to act instantly.

Another device frequently used in the advertisements is Imperative Mood which is evidenced, among others, in the phrase "It's better to share" by KFC. This phrase indicates a crafty manipulation of the idea of 'sharing' to encourage customers to buy the chicken in the 'bucket'. 
Using a natural human instinct i.e. the concept of sharing, KFC triggers the customers' intention to enjoy the festivity (Eidul Fitri) by sharing the food with their loved ones.

In summation, it can be deduced from these findings that rhetorical devices are indeed an important aspect in advertising because they accentuate the element of creativity and inventiveness in promoting the products and influencing customers' purchasing behaviour.

\section{The Use of Intertextuality}

Besides rhetorical devices, another aspect that is the focus of this study is intertextuality. The findings indicate that there are two types of intertextuality that are commonly used in the advertisements of the three fast food chains which are popular culture and socio-cultural influence.

\section{Using Popular Culture}

Based on the corpus, the researchers found that several advertisements have infused elements of popular culture. These elements include films, songs, and even popular issues through the mass media. McDonald's uses the "Spice, Spice Baby" slogan in one of their advertisements. This slogan mocks the title of a song by Vanilla Ice, an American singer, entitled "Ice, Ice Baby". This creative infusion of song lyrics in written advertisements clearly depicts the concept of intertextuality which encompasses an interplay of texts with other discourse and genres. The ingenious restructuring of the text will then prod the readers' memory of the original source of the elements which allows them to easily relate to the new text (Al-Siyami, 2013; Ali and Aslam, 2016; Chandler, 1997; Cook, 2001; Tanaka, 1994; Xin, 2000). Hence, by inserting lyrics in the advertisements, it can give customers a sense of familiarity and tap onto their memories of such elements. It may be deduced then that the 90s generation would be able to relate to the slogan with the song that they are familiar with and indirectly be interested to purchase the product.

Another example of intertextuality is the infusion of the elements of the K-pop culture in the advertisements. Currently, K-pop culture is becoming a global phenomenon (Abdul Malik Badeges, n.d; Bouelhowers, 2018; Collette-White, 2011; Dal, 2018; Fabian, 2018; Romano, 2018; Thao, 2012; Wang, 2018;). As a result, Korean drama or K-drama has taken the world with their collection of TV series which are watched by various people throughout the world. In Malaysia, K-drama is one of the phenomena that keeps growing among Malaysian viewers (Julina Tajul Ariffin , 2016; Julina Tajul Ariffin, Hassan Abu Bakar and Nor Hafezah Yusof, 2018; Zailin, 2010; Zailin Zainal Ariffin, Khalifah Osman, Ridhuan Tee, Wan Nor Aini and Mohd Nor Othman, 2013). Hence, when McDonald's produced Korean Spicy Burger, they creatively integrated the K-drama influence into their products. The advertisements mocked the posters from K-drama series. "My Love from Grill", "Burger Over Flowers", and "Descendant of the Bun" are the slogans that were adapted from the title of the K-dramas which were originally "My Love from the Star", "Boys Over Flower" and "Descendant of the Sun" (Refer to Appendices III \& IV). The innovative insertion of the K-drama titles in the food advertisements shows an obvious manipulation by the advertisers of the temporal and contextual elements which would indeed arouse the interest of the purchasers as they can create a connection to the products.

Besides that, the mass media has also highlighted a lot of controversial and popular issues. In April 2018, BBC reported that a participant in the Masterchef UK was eliminated from the show because the judges thought that the rendang dish prepared by Zaleha Kadir was not 
"crispy" enough for their liking. The remark then, has sparked the rage among Malaysian people, especially those who have been eating rendang for ages and the fact that rendang has never been or should never be crispy (Chen, 2018; Mei Chu, 2018). Seeing this opportunity as an intelligent marketing strategy, KFC has produced an advertisement for its crispy fried chicken with a statement "NOT RENDANG" as a promotional tagline (Refer to Appendix II). It was also meant to mock the issue pertaining to the Masterchef UK show. This technique is also called "parody".

In this example, intertextuality was cleverly crafted when KFC manipulates this controversial issue by injecting a sense of identity to trigger the customers' attention since this issue is only relatable to Malaysians. Moreover, the two-word tagline was sufficient to convey the covert meaning of the advertisements since a relationship has been established between the issue and the customers. This example accentuates the elements of identity and relationship in intertextuality as highlighted by Al-Siyami (2013).

\section{Using Socio-cultural Influence}

Another type of intertextuality found in the advertisements is socio-cultural influence. Malaysia, being a multiracial and multireligious country, has many festivals going on throughout the year. Most companies take this opportunity to attract their potential customers to buy their products. The same goes to the fast food chains. Every year, they will come up with products that will integrate the cultural values of certain races especially when it comes to festive seasons. It is not surprising to come across such values when analysing the influence of intertextuality in the advertisements gathered in the corpus. McDonald's has been known for its Prosperity Burger whenever the Chinese New Year is around the corner. The word "Prosperity" will always be highlighted in the advertisements to compliment the belief of the Chinese people that the new year will bring them prosperity. From the corpus, the researchers extracted a few advertisements that used Eidul Fitri festival as a part of the campaign. For instance, Texas Chicken introduced a meal for Eidul Fitri called Raya Samplers while KFC promoted their KFC Bucket "Kongsi" for Eidul Fitri campaign (Refer to Appendix I). Moreover, they also used Islamic calligraphy to enhance the Islamic celebration mood and included a crescent moon which Muslims use to indicate the beginning of the Eidul Fitri celebration. These examples clearly display how the companies make use of social images and religious symbolism to associate the products with the customers' social reality and religious identity.

These findings concur with that of Al-Siyami (2013) who studied the intertextuality of advertisements of a Saudi newspaper. She found that the advertisers invested in elements which are relatable to the readers' Islamic and Arabic identity such as registered expressions, symbols and images within the local culture. On this, Chandler (1997) highlighted that the focus on the shared experiential commonality of the buyers enhances the relationship with the brand.

\section{Possible Factors of Influence}

There are a few possible factors that could influence how the advertisements were developed. The first factor is the popularity of the fast food chain. Although the three fast food chains are well-known in Malaysia, there will always be positioning involved such as which among them is the most famous and recognized by Malaysians. One of the indicators is the number of their outlets. KFC has almost 400-500 outlets as of April 2018 (Complete List of KFC Malaysia Locations, 2018). Meanwhile, McDonald's has around 200-300 outlets nationwide (Complete List of McDonald's Malaysia Locations, 2018), while Texas Chicken has 34 restaurants around 
Malaysia (Malay Mail, 19 January 2017). A correlation can be drawn between the number of outlets and the results displayed in Table 1.

It can be deduced that KFC, with the highest number of outlets and being the first fast food name in Malaysia, may not have to invest a lot on advertisements as long as they are able to ensure that customers are satisfied and happy with their products. This concurs well with the linguistic evidence derived in this study which indicated that KFC is not investing so much on injecting 'creative' elements in their advertisements since they only used 4 types of rhetorical devices out of 14 in attracting the interest of their customers.

However, the study found that McDonald's, another favourite fast food chain in Malaysia, utilised more types of rhetorical devices in their advertisements compared to KFC. They used 9 types compared to 4 types for KFC. From these findings, it can be assumed that in order to stay in the competition, McDonald's is aware that they need to step up their game in promoting their products especially so since they are the second fast food establishment in Malaysia yet having lesser number of outlets compared to their competitor, KFC. Their advertisements need to inject creative elements to attract more potential customers to their restaurants, hence, the use of more rhetorical devices.

In Malaysia, Texas Chicken is still far behind in terms of the number of outlets which is currently 34 (Malay Mail, 19 January 2017). This is very understandable since this fast food company has just entered the Malaysian market in 2013 (Texas Chicken History, n.d.). As a new entrant in the fast food industry in Malaysia, the company realises the extent of the competition that they have to face. They really need to inform Malaysians of their existence and promote their products as well as attract them to try the new food. To achieve this, they utilise elements of 'creativity' and 'intertextuality' in promoting their products. These efforts are clearly depicted in the use of rhetorical devices employed in their advertisements. In reference to Table 1, it can be seen that advertisements by Texas Chicken recorded the highest frequency in the use of rhetorical items in this study which is 66 for 9 types of devices.

\section{Halal Logo as a Rhetorical Device}

Apart from tackling the customers through advertisements, it is also very common for products that are being sold in Islamic countries to have its Halal recognition, both on the products and in the advertisements. Consumers are more prone to favour advertisements that have Halal certification and recognition compared to those without the Halal sign (Ariffin, Shah and Ismail, 2016; Shaizatulaqma, Khairul Anwar and Ishak, 2016).

Based on the corpus used in this study, there are several advertisements that included Halal logo and Halal slogan. Malaysia's KFC, Texas Chicken, and McDonald's have been very supportive and informative about their Halal status to attract more consumers to try their food without any hesitation. They are using Halal logo and Halal slogan as an imperative mood to suggest and propose to the customers that their products are safe to be consumed and they are Shari'ah compliant. In 2013, McDonald's reputation was tarnished due to speculations of nonHalal ingredients in its products which resulted in massive boycott among the citizens especially the Muslims (Ana Ghoib, 2103; Mei Chu, 2013; The Star Online 21 Sept 2013). Hence, to gain customers' confidence, most fast food chains in Malaysia are using Halal logo in their advertisements as an effort to ensure that their potential customers, especially Muslims, will not have doubts while enjoying their food. 


\section{Conclusion}

The findings from this study clearly accentuate the functions of rhetorical devices in creating impactful advertorials as utilized by the three fast food chains (KFC, McDonald's, and Texas Chicken) in promoting their products.

Besides that, it also highlights on the possible relationship between the use of the rhetorical devices in the advertisements and the level of prominence of the companies in Malaysia. Moreover, the use of popular cultures and socio-cultural influences have been identified as part of the intertextual elements in their advertisements to enhance the memorability of the audience towards the products and create an association with their identity. It was also found that Halal logo has become an important rhetorical device to give assurance to Muslim customers on the quality and permissibility of the food products. This analysis has proven that despite some claims, creative linguistic devices such as rhetorical devices and intertextuality are very much prevalent in online advertisements as working devices to attract customers.

\section{Acknowledgement}

This study received the financial support from the Ministry of Education, Malaysia (FRGS/1/2018/SSI01/UIAM/03/1).

\section{References}

Ali, A., \& Aslam, A. (2016). Intertextuality: An effective tool in selling products through advertisements. PUTAJ - Humanities and Social Sciences, 141-150.

Al-Siyami, A. (2013). Intertextuality in newspaper advertising. Journal of Modern Languages 23(1), 41-56.

Ana Ghoib. (2013). McDonald's Malaysia nafi guna mayonis dan sos 'lemak babi' ML10 (McDonald's deny using lard in mayonnaise and sauce). Retrieved from https://www.malaysianreview.com/27023/mcdonalds-malaysia-nafi-guna-mayonissos-lemak-babi-lm10/

Ariffin, S. K., Shah, K. A., \& Ismail, I. (2016). Muslim consumers' attitudes toward the advertisement of non-certified coffee shops. Jurnal Pengurusan 48, 111-123.

Abdul Malik Badeges. (n.d). The global phenomenon of the k-pop culture: The case of music industry in Malaysia. Unpublished thesis. University of Malaya.

Bhatia, V. (2005). Generic patterns in promotional discourse. Persuasion across genres: A linguistic approach, 213-225.

Bouelhowers, M. (2018). Will k-pop conquer the world?. Retrieved from https://www.diggitmagazine.com/papers/will-k-pop-conquer-world

Burgersa, C., Konijn, E. A., Steen, G. J., \& Iepsma, M. A. (2015). Making ads less complex, yet more creative and persuasive: The effects of conventional metaphors and irony in print advertising. International Journal of Advertising 34(3), 515-532.

Chandler, D. (1997). Semiotics for beginners. Retrieved from http://www.aber.ac.uk/media/Documents/S4B/sem01.html

Chen, H. (2018). Malaysians roast Masterchef over chicken rendang elimination. BBC News (3 April 2018).

Collette-White, M. (2011). Korean pop music out to conquer the world. Retrieved from https://www.reuters.com/article/us-asia-west-idUSTRE7AS0WS20111129

Complete List of KFC Malaysia Locations. (2018, April 07). Retrieved from AggData: https://www.aggdata.com/aggdata/complete-list-kfc-malaysia-locations 
Complete List of McDonald's Malaysia Locations. (2018, March 18). Retrieved from AggData: https://www.aggdata.com/aggdata/complete-list-mcdonalds-malaysia-locations

Cook, G. (2001). The discourse of advertising. New York: Routledge

Dal Yong Jin. (2018). An analysis of the Korean wave as transnational popular culture: North American youth engage through social media as tv becomes obsolete. International Journal of Communication, 12, 404-422.

Elmo Raj, P. P. (2015). Text/texts: Interogating Julia Kristeva's concept of intertextuality. Research Jounal of Humanities \& Social Sciences, vol.3, 77-80.

Fabian. (2018). Watch out for the Korean wave. Retrieved from https://www.asiaexchange.org/blogs/author/fabian/

Fairclough, N. (1993). Critical discourse analysis and the marketization of public discourse: The universities. Discourse \& Society 4(2), 133-168.

Fast Food Industry Analysis (2018). Retrieved from https://www.franchisehelp.com/industryreports/fast food-industry-analysis-2018-cost-trends/

Fredericks John, D.A. (2015). Language choice and ideology: Examining the use of the Malay language in English newspaper advertisements in Malaysia. Language and Communication, 43, 87-101. DOI: http://dx.doi.org/10.1016/j.langcom.2015.05.004

Hamisah H., Ezhar T., Jusang B., Mohd Nizal M.N. \& Azhani A., (2016). An exploratory study on the relationship between involvement and attitude towards tv advertisements with Islamic symbols and purchase intent. Malaysian Journal of Communication, 32(2), 817831 .

Harris, R. A. (2016). Writing with clarity and style: A guide to rhetorical devices for contemporary writers. Routledge.

Hartnett, N., Kennedy, R., Sharp, B., \& Greenacre, L. (2016). Creative that sells: how advertising execution affects sales. Journal of Advertising 45(1), 102-112.

Julina T. A. (2016). Korean television drama in attracting Malaysian audiences: media strategy perspective. International Journal of Engineering Research and Management, vol.3, issue 7, 38-42.

Julina T. A., Hassan A. B. \& Nor Hafezah Y. (2018). Culture in Korean drama towards influencing Malaysian audiences. International Journal of Innovative Research in Engineering and Management, vol.5, issue 1. Doi:10.21276/ijirem.2018.5.1.3

Kim, A.J. \& Ko, E. (2012). Do social media marketing activities enhance customer equity? An empirical study of luxury fashion brand. Journal of Business Research, 65, 1480-1486.

Mazzali-Lurati, S. \& Lurrati, C. (2016). Blending metaphors and arguments in advertising. In F. Ervas and E. Gola (Eds.). Metaphor and Communication, 498-525, Amsterdam: John Benjamins.

McD: All products certified halal. The Star Online (21 Sept 2013).

McQuarrie, E.F. \& Mick, D.G. (2009). Visual and verbal rhetorical figures under directed processing versus incidental exposure to advertising. Journal of Consumer Research 29(4), 579-587.

Mei Chu, M. (2013). The truth behind McDonald's non-halal sauces. Retrieved from https://says.com/my/news/mcdonalds-malaysia-is-halal-no-lm-10-ingredient-in-sauces

Mei Chu, M. (2018). 'Rendang has to be crispy', MasterChef UK moment riles up Malaysians. The Star Online (2 April 2018).

Michalik, U., \& Michalska-Suchanek, M. (2016). The persuasive function of rhetoric in advertising slogans. Journal of Accounting and Management 6 (1), 45-58.

Miller, D., \& Toman, M. (2015). An analysis of rhetorical figures and other linguistic devices in corporation brand slogans. Journal of Marketing Communications. 
Nemcokova, K. (2014). Multigeneric intertextuality in advertising: Discourse strategy from a cognitive perspective. Topics in Linguistics 13.

Pangali, P. (2006). Westernisation of Asian diets and the transformation of food system: implication for research and policy. In Chris Ryan, Hazrina Ghazali and Asad Mohsin. (2011). Determinants of intention to leave a non-managerial job in the fast food industry in West Malaysia. International Journal of Contemporary Hospitality Management Vol 23, no.3, pp. 344-360.

Prentice, M. \& Barker, M. (2017). Intertextuality and interdiscursivity. Oxford bibliographies. DOI: $10.1093 / \mathrm{OBO} / 9780199766567-0171$

Rahm, H. (2006). Getting attention in the media: Interdiscursivity and ideology in advertisements. In I. Lassen, J. Strunck, \& T. Vestergaard. (Eds.). Mediating ideology in text and image: Ten critical studies. Amsterdam: John Benjamins.

Romano, A. (2018). How K-pop become a global phenomenon. Retrieved from https://www.vox.com/culture/2018/2/16/16915672/what-is-kpop-history-explained

Shaizatulaqma K.A., Khairul Anwar M.S. and Ishak I. (2016). Muslim consumers' attitudes toward the advertisement of non-certified coffee shops. Journal Pengurusan, 48, 111 123. DOI:http://dx.doi.org/10.17576/pengurusan-2016-48-09

Skorupa, P., \& Duboviciene, T. (2015). Linguistic characteristics of commercial and social advertising slogans. Coactivity: Philology, Educology/Santalka: Filologija, Edukologija, 23(2), 108-118.

Tanaka, K. (1994). Advertising language: A pragmatic approach to advertisements in Britain and Japan. London: Routledge.

Texas Chicken History. (n.d.). Retrieved from http://www.texaschickenmalaysia.com/texaschicken-history/

Texas Chicken to open more outlets in northern region of Peninsular Malaysia. (2017, January 19). Retrieved from Malay Mail: https://www.malaymail.com/s/1296313/texaschicken-to-open-more-outlets-in-northern-region-of-peninsular-malaysia

Thao E.D. (2012). Emergence of the Korean popular culture in the world. Thesis. Turku University of Applied Sciences. Retrieved from https://www.theseus.fi/bitstream/handle/10024/42870/Do_Thao.pdf?

Tom, G., \& Eves, A. (1999). The use of rhetorical devices in advertising. Journal of Advertising Research, 39-43.

Wang, A.X. (2018). How K-pop conquered the West. Retrieved from https://www.rollingstone.com/music/music-features/bts-kpop-albums-bands-globaltakeover-707139/

Wolk, A. (2018, March 05). While Advertising Slept: 6 Reasons The Ad Industry Got Sucker Punched By Digital. Retrieved from Forbes Magazine: https://www.forbes.com/sites/alanwolk/2018/03/05/while-advertising-slept-sixreasons-the-ad-industry-got-sucker-punched-by-digital/\#3f487d66445e

Wu, J. (2011). Understanding interdiscursivity: A pragmatic model. Journal of Cambridge Studies, vol.6, no.2-3, 95-115.

Xin, B. (2000). Intertextuality from a critical perspective. Suzhou: Suzhou University Press

Zailin Z.A. (2010). The relationship between American popular culture and some selected aspects of consumer behavior: A study of Malaysian adolescents. $\mathrm{PhD}$ thesis, Faculty of Business and Accountancy, University of Malaya, Kuala Lumpur, Malaysia.

Zailin Z. A., Khalifah O., Ridhuan T. A., Wan Nor Aini W.M.A. \& Mohd Nor Othman. (2013). Analysing the dimension of Korean popular culture among Malaysian adolescents. Conference proceedings for the $5^{\text {th }}$ International Conference on Humanities and Social Sciences, Faculty of Liberal Arts, Prince of Songkla University. 
Zhang, C., Lorache, M. \& Richard, M.O. (2017). The differential roles of verbs, nouns and adjectives in English and Chinese messages among bilingual consumers. Journal of Business Research, 72, 127-135.

\section{Appendices}

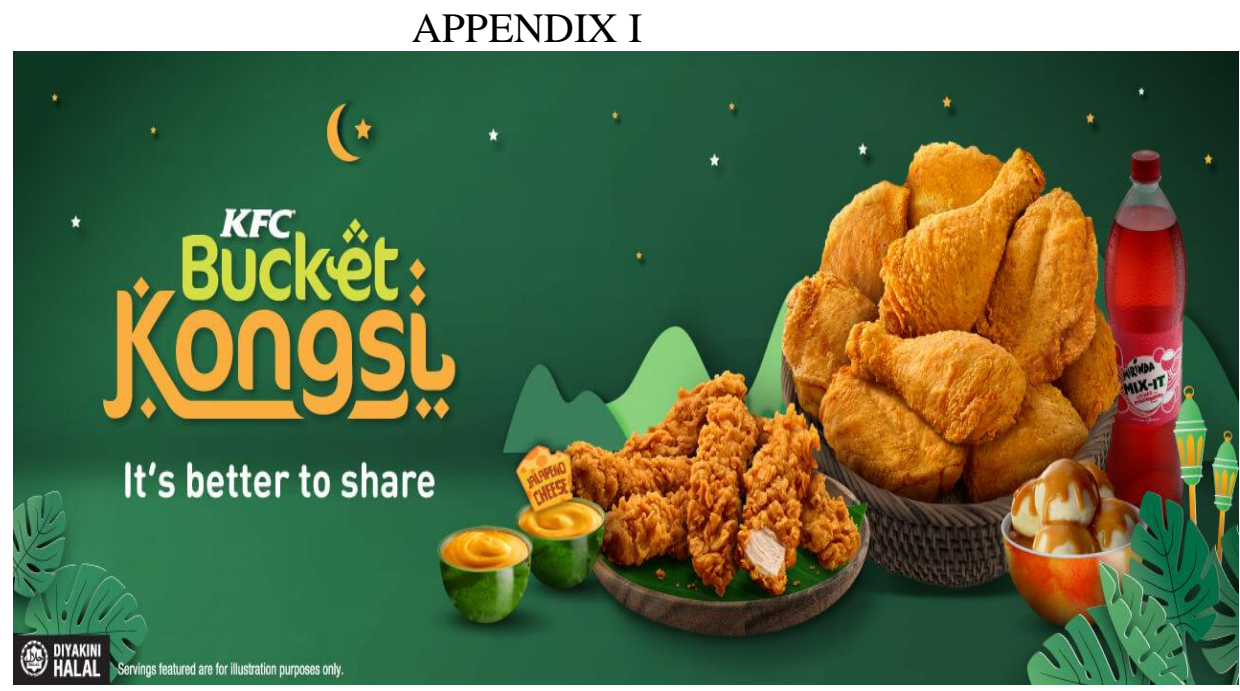

APPENDIX II

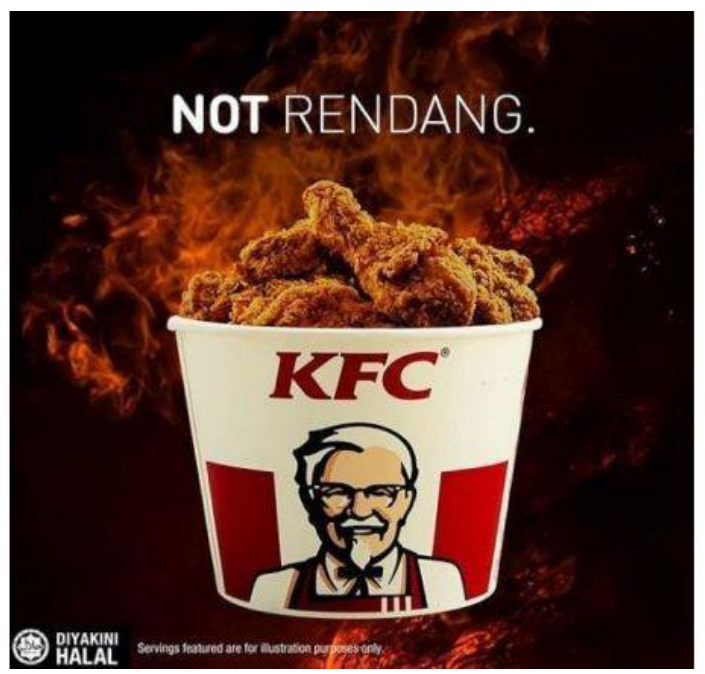

APPENDIX III 


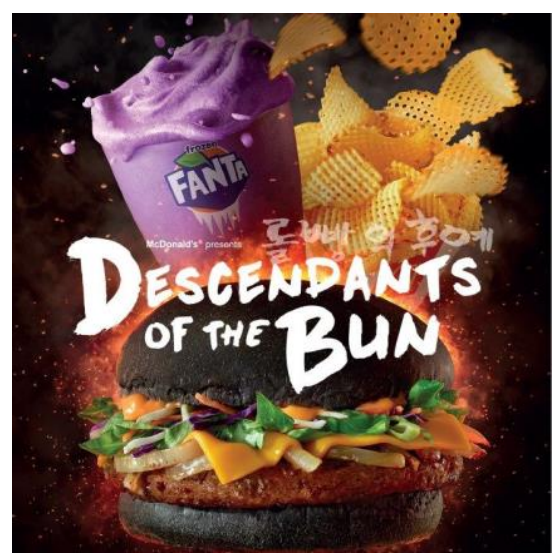

APPENDIX IV

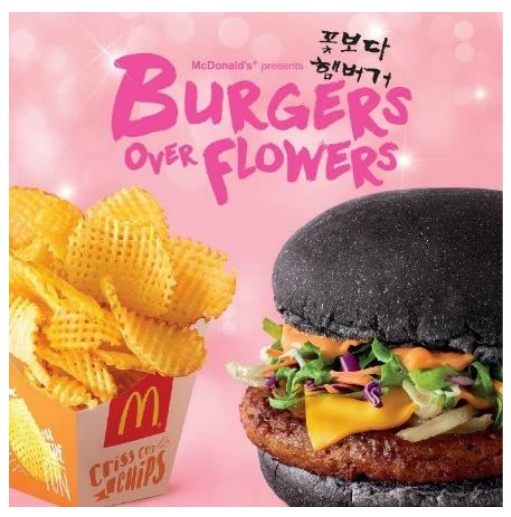

APPENDIX V

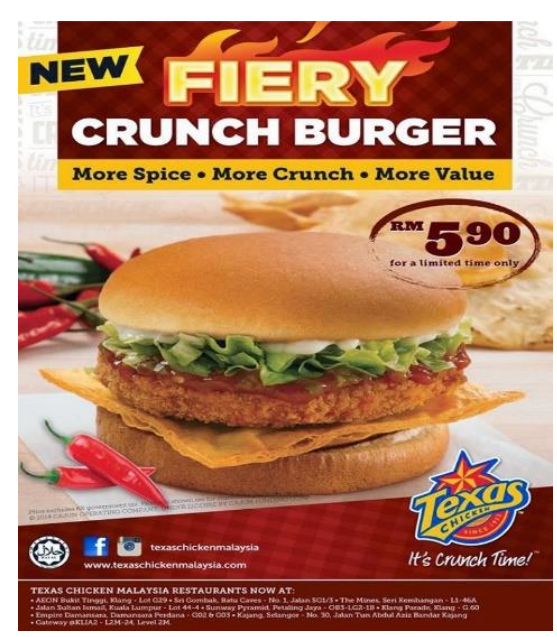


APPENDIX VI

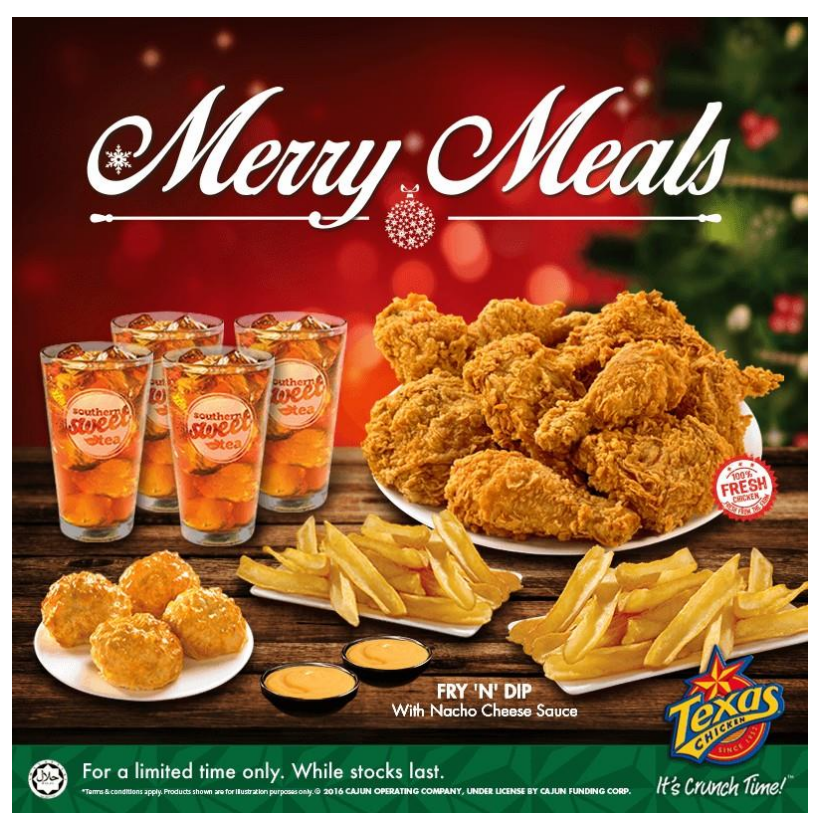

